\title{
2 Solar and Geothermal Energies Are Sustainable; Nuclear Power Is Not
}

\author{
Alejandro de las Heras \\ Independent Researcher \\ Eduardo Rincón-Mejía \\ Autonomous University of Mexico City \\ Behrooz Sani \\ Independent Researcher \\ Marina Islas-Espinoza \\ Mexico State University
}

\section{CONTENTS}

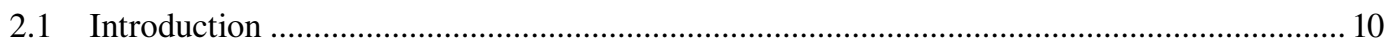

2.2 Enough Solar Energy to Fuel 10,000 Earths ................................................................. 10

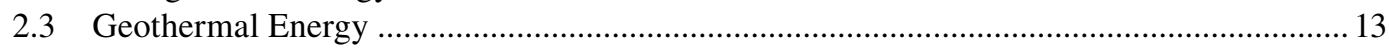

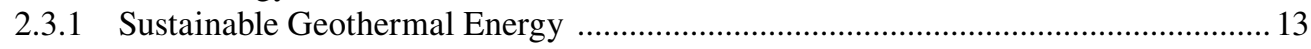

2.4 Nuclear Power: Dream Foiled ................................................................................... 14

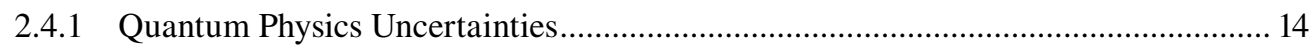

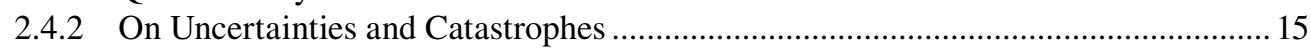

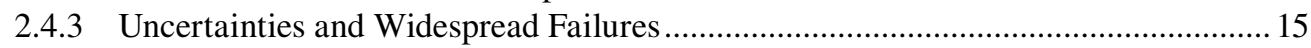

2.4.3.1 Criticality and Load Factor .................................................................... 15

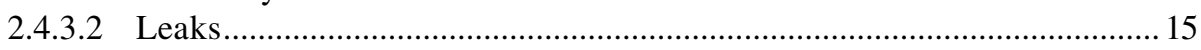

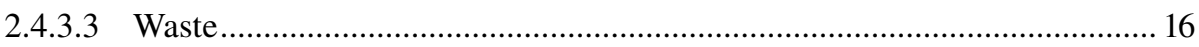

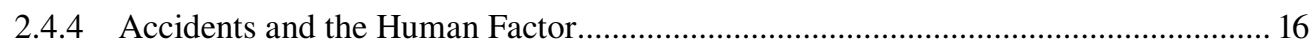

2.4.5 Nondemocratic Practices ........................................................................................... 16

2.4.6 Small Modular Reactors: Killed in the U.S., a Return Would Spread the Issues....... 19

2.4.7 Medical and Scientific Uses Require Few Reactors ................................................... 19

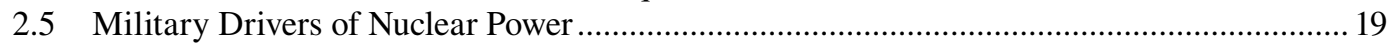

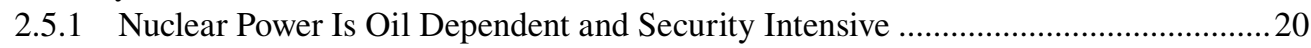

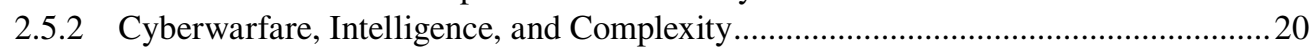

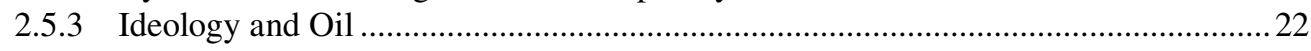

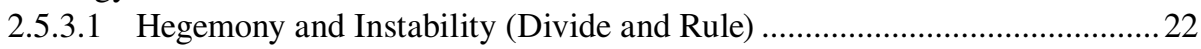

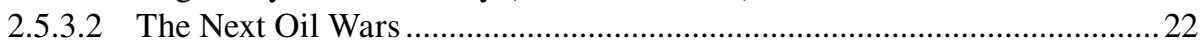

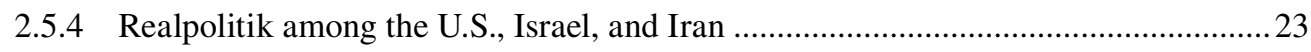

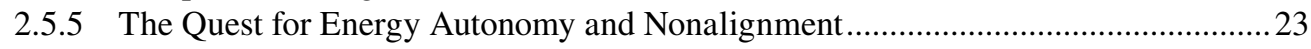

2.5.5.1 Security Lessons from Chernobyl ................................................................ 23

2.5.5.2 Security Lessons from Furdu....................................................................24

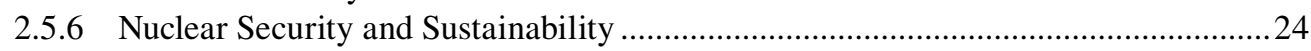

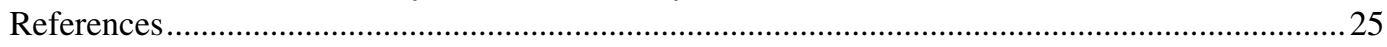




\subsection{INTRODUCTION}

Nuclear fusion taking place in the sun is safe to use directly as photovoltaic (PV) and concentrated thermal energy or indirectly as wind, wave, or tide energy. Nuclear decay in the Earth's interior is also harnessed, with Iceland setting the pace for reliable whole-country supply of geothermal energy. Conversely, nuclear fission is an ill-understood process making nuclear technologies' failures surprisingly regular.

This chapter addresses the sustainability of the foregoing types of radiation energy sources. It first highlights the supply of incident solar energy that can power the geosphere and biosphere and cater to the needs of a thriving future human civilization. Second, the technological conditions for sustainable geothermal energy (SGE) are examined. Third, while discounting weak antinuclear arguments (public perceptions), it shows the absence of technical conditions for sustainable fission nuclear power.

\subsection{ENOUGH SOLAR ENERGY TO FUEL 10,000 EARTHS}

In its orbit around the sun, during each nonleap year Earth intercepts an amount of energy equal to the solar constant $G_{S}=1360.8 \pm 0.5 \frac{\mathrm{W}}{\mathrm{m}^{2}}$ (Kopp and Lean, 2011) multiplied by the area of a circle with Earth's mean radius $R_{T}=6.371 \times 10^{6} \mathrm{~m}$, times the duration of a year in seconds

$$
\begin{aligned}
E_{S} & =G_{S}\left[\pi R_{T}^{2}\right][\text { year }]=\left(1360.8 \frac{W}{m^{2}}\right)\left[\pi\left(6.371 \times 10^{6} \mathrm{~m}\right)^{2}\right]\left(3.1536 \times 10^{7} \mathrm{~s}\right) \\
& =5.472251 \times 10^{6} \mathrm{EJ}
\end{aligned}
$$

This is almost 10,000 times more than the energy consumed globally $\left(\sim 5.504 \times 10^{2} \mathrm{EJ}\right.$ in 2015$)$ (BP, 2016), enough to meet present and future needs with very few or no emissions to the geosphere and the biosphere. As a reminder, $1 \mathrm{EJ}$ is $10^{18} \mathrm{~J}$.

But $\sim 30 \%$ of this solar energy is reflected by clouds, ice, and Earth's surface (a factor known as albedo), so the solar energy caught by Earth is

$$
E_{S \text { caught }} \cong\left(5.472251 \times 10^{6} \mathrm{EJ}\right)(1-0.30)=3830576 \mathrm{EJ}
$$

And since $\sim 19 \%$ of the solar radiation is absorbed by the atmosphere, the solar radiation that finally reaches the Earth's surface, the gross solar potential (GSP) is

$$
G S P \cong(5472251 \mathrm{EJ})(1-0.30-0.19) \approx 2,790,848 \mathrm{EJ}
$$

Most of this energy, in thermal form, is required to move Earth's oceans and atmosphere. The photosynthetically active radiation (i.e., the visible range) is used by algae, plants, and bacteria.

If we assume conservatively that only one-hundredth of this energy could be sustainably utilized with future efficiencies close to the thermodynamic limit, the sustainable solar potential would be $\sim 27,900 \mathrm{EJ}$, more than 50 times the current world energy consumption.

The technical potential is an even lower figure given by the second law of thermodynamics (no thermal machine is $100 \%$ efficient); by current mature and emerging technologies, not speculative ones; and by other practical limitations, including the environmental ones. Considering that $29 \%$ of the terrestrial surface is mainland, and assuming that $0.1 \%$ of this surface can be populated with PV modules with $16 \%$ mean sunlight-to-electricity conversion efficiency, and another $0.1 \%$ can be populated with solar thermal collectors with $60 \%$ mean thermal efficiency, the current technical solar potentials (TSPs) $T S P_{\text {electric }}$ and $T S P_{\text {thermal }}$ would be in the order of

$$
T S P_{\text {electric }} \cong(2,790,848 \mathrm{EJ})(0.29)(0.001)(0.16) \cong 129.50 \mathrm{EJ}
$$

and 


$$
T S P_{\text {thermal }} \cong(2,790,848 \mathrm{EJ})(0.29)(0.001)(0.60) \cong 485.60 \mathrm{EJ}
$$

These two conservative technical potentials combined exceed the current world energy consumption, so in principle, all fossil and nuclear plants could be abandoned much before 2050 by using only conventional solar technologies. Assuming a capacity factor of 0.20 , an acceptable mean value encompassing all latitudes for current PV technologies, the $T S P_{\text {electric }}=129.50$ EJ shown in equation (2.4) would correspond to a $\sim 20.5 \mathrm{TW}$ installed capacity. Considering all technical, infrastructure, economic, and policy barriers to be overcome, it is feasible to reach $10 \mathrm{TW}$ by 2030 (Haegel et al., 2017).

Green plants convert solar energy with sunlight-to-bioenergy efficiencies greater than $2 \%$ (Bonner, 1962), but much larger efficiencies have been recorded in algae and phytoplankton (Ryther, 1959). The thermodynamic knowledge of photochemical solar energy conversion efficiencies is now at an advanced stage (De Vos, 1995). A very conservative estimate of a mean photochemical solar efficiency would be $1 \%$ for all photosynthetic organisms. Considering a photosynthetic cover on $50 \%$ of the oceans and land, the gross bioenergy potential (GBP) can be in the order of

$$
G B P \approx(G S P)(0.01)(0.21)(0.5)(2)=5860.78 \mathrm{EJ}
$$

The current rate of energy capture by photosynthetic processes seems to be $130 \mathrm{TW}$ (Steger et al., 2005), which corresponds to 4099.68 EJ, 30\% less than the estimate in Equation 2.6. This potential must factor in reforestation and sustainable agroforestry using perennial plants. It has just been discovered (Bastin et al., 2017) that drylands, which occupy more than $40 \%$ of Earth mainland, have much more extensive forest than previously reported and cover a total area similar to that of tropical rainforests or boreal forests. This increases estimates of global forest cover by at least $9 \%$, approaching the GBP to that given in Equation 2.6. This does not even account for the very extensive soil biological crusts and their photosynthetic role. The current technical bioenergy potential could conservatively be as large as $1 \%$ of GBP, which would amount to 59 EJ.

To understand the amount of photosynthetic activity on Earth, one must realize that it converts $\sim 110$ billion metric tons of carbon into biomass each year (Field et al., 1998). Fossil fuels were all formed during hundreds of million years with biomasses nourished by solar energy via photosynthesis with relatively low solar-biomass energy efficiencies.

Most of the bioenergy potential is used in endoenergetic (metabolic) needs, and only a residual portion could be used for human exoenergetic applications. The annual human endoenergetic consumption of 10 billion people much before 2100, assuming $100 \mathrm{~W}$ per capita metabolic consumption would be

$$
H E E C \cong\left(100 \frac{W}{\text { inhabitant }}\right)\left(10^{10} \text { inhabitant }\right)\left(3.1536 \times 10^{7} \mathrm{~s}\right)=31.54 \mathrm{EJ}
$$

This is $\sim 0.5 \%$ of the GBP, but the energy needs of thousands of other species limit the amounts of bioenergy that could be dedicated to human exoenergetic consumption. Finally, deforestation and land use emissions since 1850 have totaled $\sim 660 \mathrm{Gt} \mathrm{CO}_{2}$; this figure provides an upper limit to the physical potential for reforestation to capture $\mathrm{CO}_{2}$ (National Research Council, 2015). Estimating that complete afforestation is rather unrealistic, and that deforestation emissions have been a tenth of those from fossil fuel consumption, we must not rely solely on reforestation to return to $350 \mathrm{ppm}$ atmospheric $\mathrm{CO}_{2}$ in the medium term.

Now, as mentioned in Chapter 17, 1\% of the solar energy caught by Earth is converted into wind energy (Peixoto and Oort, 1992). Then the gross wind potential (GWP) can be estimated as

$$
G W P \cong 0.01 E_{S \text { caught }}=38,306 \mathrm{EJ}
$$


Using wind turbines with power coefficients $\mathrm{Cp}=0.50$, harvesting $0.5 \%$ of this GWP gives the approximate current technical wind potential (TWP):

$$
T W P \cong(0.50)(0.005) G W P=95.77 \mathrm{EJ}
$$

These and other gross and technical potentials for most renewable sources of energy as well as their current utilization are summarized in Table 2.1.

In Table 2.2, the proved reserves of oil, natural gas, and coal are shown. By total proved reserves, we mean those quantities that geological and engineering information indicate, with reasonable certainty, can be recovered under existing economic and operating conditions. The reserves/extraction $(\mathrm{R} / \mathrm{E})$ ratio is the expected time that a proved reserve would last if extraction were to continue at the rate of the last year of extraction.

If those proved reserves are expressed in their energetic content in EJ, the magnitude of the oil reserves is 8,877.10 EJ, the gas reserves contain 6,933.15 EJ, and the carbon ones have 18,327.78 EJ. Altogether, they have an energetic potential of 34,138 EJ. The GSP of 1 year is more than 80 times larger. In other words, in just 5 days, the terrestrial surface receives more solar energy than is contained in all fossil proved reserves.

Knowledge of thousands of main sequence stars like our sun, also known as dwarves, indicates that it will not start growing for at least another 3 billion years, following which life on Earth will be wiped out. And so, the potential of solar energy is, for all practical purposes, infinitely greater than that of all fossil energy sources. Nuclear materials, like uranium and thorium, have even smaller potentials than those of fossils: all nonrenewable sources of energy are insignificant compared to solar and other renewable sources. According to Table 2.2, fossil (and nuclear) sources cannot supply energy for much more than half a century. Therefore, their consumption at current rates, even ignoring the deadly pollution that their use entails, is unsustainable.

\section{TABLE 2.1}

\section{Estimated Gross and Technical Potentials of Main Renewable Energy Sources}

\begin{tabular}{lccc} 
Energy Source & $\begin{array}{c}\text { Gross Potential } \\
\text { (EJ/year) }\end{array}$ & $\begin{array}{c}\text { Current Technical Potential } \\
\text { (EJ/year) }\end{array}$ & $\begin{array}{c}\text { Supply in 2016 (EJ) } \\
\text { Solar } \\
2,790,848\end{array}$ \\
& & $T S P_{\text {electric }} \approx 129.5$ & 1.5 \\
Wind & 38,306 & $T W P_{\text {thermal }} \approx 485.6$ & $1.38[12]$ \\
Geothermal & $1,400[13]$ & 60 & 3.15 \\
Bioenergy & $5,860.78$ & 59 & 0.34 \\
Ocean tidal & $75.69[14]$ & $4.67[15]$ & $9.41[12]$ \\
Ocean surface currents & $255.44[16]$ & $0.473[17]$ & 0.004 \\
Hydropower & $365.82[18]$ & $51.40[19]$ & - \\
Total & $2,837,111.73$ & 886.41 & $37.38[1]$ \\
& & & 53.16 \\
\hline
\end{tabular}

TABLE 2.2

Proved Reserves of Fossil Fuels and Relation Reserve/Extraction

$\begin{array}{lllc}\text { Energy Source } & \text { Total Proved Reserves } & \text { Extraction in 2015 } & \text { R/E (Years) } \\ \text { Oil } & 1697.6 \times 10^{9} \text { barrels } & 34.6779 \times 10^{9} \text { barrels } & 48.95 \\ \text { Natural gas } & 186.9 \times 10^{12} \mathrm{~m}^{3} & 3538.6 \times 10^{9} \mathrm{~m}^{3} & 52.82 \\ \text { Coal } & 437,749 \text { mtoe } & 3839.9 \text { mtoe } & 114\end{array}$

Source: BP, Statistical Review of World Energy, 65th ed., BP plc, London, 2016. 


\subsection{GEOTHERMAL ENERGY}

Geothermal energy is Earth's heat that can be exploited by technology. This heat source is mostly due to residual planetary accretion heat and radioactive decay of uranium isotopes $\left({ }^{238} \mathrm{U},{ }^{235} \mathrm{U}\right)$, thorium $\left({ }^{232} \mathrm{Th}\right)$, and potassium $\left({ }^{40} \mathrm{~K}\right)$ (Lubimova, 1968). At present, the planet undergoes slow net thermal loss to space (minus $300^{\circ} \mathrm{C}-350^{\circ} \mathrm{C}$ every 3 billion years, with a current temperature of $4000^{\circ} \mathrm{C}$ at the bottom of Earth's mantle). Outgoing heat flows are $44.5 \mathrm{TW}$ from Earth, out of which 19\% escape from the radioisotope-richer crust, $77 \%$ from the mantle, and the remainder from the nonradioactive core (Stacey and Loper, 1988). Half of the mantle's heat is radiogenic. The total heat content of Earth is $12.6 \times 10^{24} \mathrm{MJ}$ (Armstead, 1983), equivalent to 3.3 years of solar energy captured by Earth.

Current technologies tap convective hydrothermal systems (liquids or steam) and conductive geothermal systems (hot rock). Larderello, Italy, in 1904 was the first spot to be utilized, both as a source of direct thermal energy and in electricity generation. By 1928, Iceland started to exploit hydrothermal sources.

\subsubsection{Sustainable Geothermal Energy}

Several conditions that appear to be linked to SGE are as follows:

- Although renewable, crust heat is often withdrawn 10 times faster than its replacement rate. Pressure can decline and cold water can permeate into the geothermal reservoir (World Energy Council, 2016).

- SGE microgeneration by end users (mostly ground source heat pumps) reduces transport costs and attendant heat losses but often requires artificial wells. Drilling economic and environmental costs need to be gauged against longer-term sustainability. These costs can be modest since drilling is limited to shallow depths where the sun drives the temperature difference that allows for ground source geoexchange technologies.

- Natural sources are frequently large and become the hub of centralized networks with extensive piping subject to corrosion.

- Pollutants threaten aquifers. SGE must differ from practices in unsustainable technologies: fracking (shale gas hydraulic fracturing) uses many pollutants, such as biocides that limit microbiologically enhanced corrosion of piping and equipment (Sovacool, 2014). Such biocides only work until microbes develop resistance and contribute to the global health problem of antibiotic resistance.

- Natural wells and deep artificial ones often bring to the surface brine containing potentially toxic metals (Baba et al., 2008), including naturally occurring radioactive material (IAEA, 2013). The brine must be recycled in situ, after recovery of pollutants (Premuzic et al., 1995), all of which are useful. Brine recycling has the advantage of reducing its mineralization thereby augmenting the amount of available heat (World Energy Council, 2016).

- Stock must be taken of seismicity lessons from other energy technologies (nuclear power, large hydropower, fracking): local seismicity hazards endanger both the environment and utilities; these in turn affect natural seismicity.

- Invasive methods aiming at reservoir stimulation (chemically enhancing permeability, thermal cracking, or deflagration) (World Energy Council, 2016) put reservoirs and aquifers at chemical and mechanical risk.

Solutions exist for all the above. In particular, Enel S.p.A.'s stillwater solar PV-concentrating solargeothermal hybrid plant in Nevada has extended the life of the geothermal reservoir, reduced injections of water in a water-scarce area, and recycled and reheated spent brine into the reservoir. Also, coiled tube and wirelines can successfully reduce costs of mineral scale removal (World Energy Council, 2016) without using biocides. 


\subsection{NUCLEAR POWER: DREAM FOILED}

The Anthropocene Epoch started around 1950 when a layer of radioactive plutonium and ${ }^{14} \mathrm{C}$ fallouts covered, indelibly, the entire globe, following nuclear arms experiments (Clarke et al., 2012; University of Leicester Press Office, 2016). As to civil nuclear power, it would only be acceptable if it met proper conditions. But does it?

According to the nuclear industry, the most lethal nuclear meltdown so far, Chernobyl in 1986, led to 58 deaths (World Nuclear Association, 2016). However, independent researchers report that in Belarus, Russia, and Ukraine alone, an estimated 200,000 additional deaths resulted from the catastrophe during 1990-2004 (Greenpeace, 2006). This order of magnitude difference between the industry and independent assessments forces a step back and a thorough examination of sustainability of nuclear power.

There is overwhelming evidence that current and proposed nuclear power technologies should end as sources of energy (Rincón, 2011). For Arnie Gundersen, a former nuclear industry senior vice president and licensed reactor operator "the evidence proves that new nuclear power plants will make global climate change worse due to huge costs and delayed implementation periods. Lift the $\mathrm{CO}_{2}$ smoke screen and implement the alternative solutions that are available now, faster to implement and much less expensive" (Gundersen, 2016).

The nuclear power industry in fact is facing economic challenges, with renewables reaching lower electricity costs than nuclear power (Chapter 1) and resistance to protracted nuclear projects that have much hindered the expansion of the industry since around 2000 in Europe and Eurasia, the U.S., and the Asia-Pacific regions (Figure 2.1). Biological unsustainability of nuclear power is addressed in Chapter 20. In the remainder of this section, the main scientific and technological issues of nuclear power are reviewed.

\subsubsection{Quantum Physics Uncertainties}

The current explanation of nuclear fission is a quantum tunneling process. As such, it has a Schrödinger equation of the probability $(>0)$ of anything happening, in this case neutrons escaping
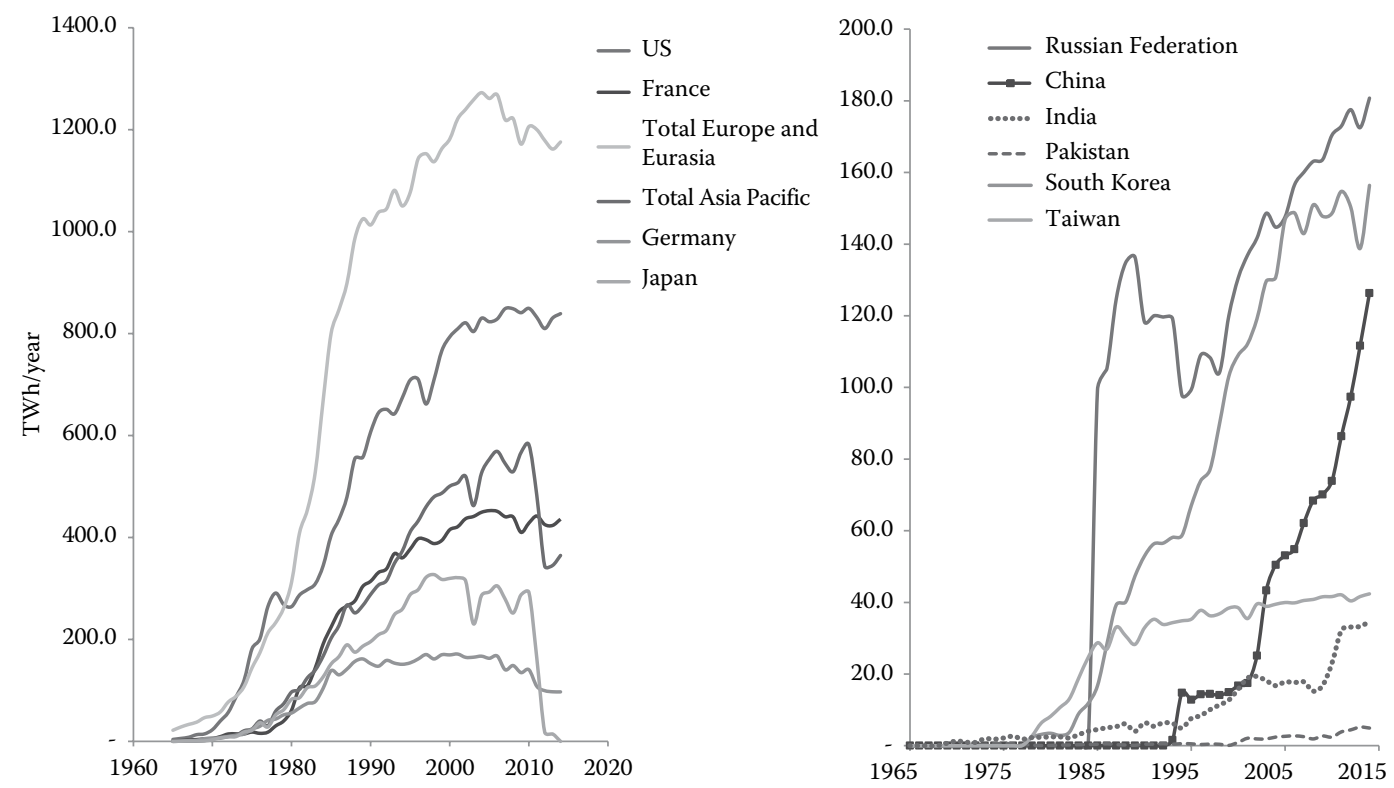

FIGURE 2.1 Nuclear power plants: installed capacity and stalled growth trend among main nuclear power users. (From BP, Statistical Review of World Energy, 65th ed., BP plc, London, 2016.) 
the strong nuclear force binding them to protons. Knowledge gaps are still disturbing: there is a dearth of "complete fission theory, many puzzles are yet unsolved" (Al-Adili et al., 2015). "Quantitative understanding [of the nuclear fission process] remains elusive" even though "many nuclear applications as well as fundamental research rely on a precise description of fission data" (Talou et al., 2015). "Exact models are seldom available in nuclear physics. Good agreement between different models (precision) does not guarantee that they are near the truth; all models can be systematically off due to missing knowledge," and "systematic uncertainties, on the other hand, are very tough to assess" (Ireland and Nazarewicz, 2015).

\subsubsection{ON UnCertainties AND Catastrophes}

The Schrödinger probability argument also applies to accidents: The clearest example of a nonnull (Schrödinger) probability for any event, however complex and unlikely, was the catastrophic loss between March 12 and March 15, 2011, of Fukushima Daiichi reactors 1-4 (in that order): following the earthquake, steel towers collapsed, external power was interrupted; then following the tsunami, the emergency diesel generators stopped and the diesel tanks were washed away. Battery power was then exhausted and the "normal" heat release to the sea was cut off; the cooling function in spent fuel pools continued to be lost until the fuel rods became exposed to air; they heated rapidly and their cladding reacted with water producing vast amounts of hydrogen, raising the pressure; not even venting impeded a hydrogen explosion that blew the reactor 1 building apart. At reactor 2, unstable cooling via the steam-driven Reactor Core Isolation Cooling system stopped and the fuel became exposed to air and totally released. At reactor 3, coolant injection failed, not permitting the Reactor Core Isolation Cooling to operate and raising the pressure; later, when the spent fuel pool water evaporated, the rods became exposed to air, producing a hydrogen explosion that destroyed the building. At reactor 4, a similar spent fuel pool cooling failure led to a hydrogen explosion that also tore apart the building (Great East Japan Earthquake Taskforce \& Science Council of Japan, 2011). Clearly, the builders of Fukushima's redundant systems did not manage to make them independent of each other or able to withstand a common (seismic) shock, despite decades of modeling the effects of common cause failures on redundant systems.

\subsubsection{UnCERTAinties AND WidesPreAd FaILUReS}

\subsubsection{Criticality and Load Factor}

Theories also have failed to predict normal reactor behavior: unpredictable variations in parameter $\mathrm{K}$ (the reproduction rate of the fission reaction) seem linked to still ill-understood load factors of nuclear reactors below $65 \%$ on average (the load factor is the ratio of the power produced in a year to the nominal capacity without downtimes) (Cowan, 1990). In other words, technology is not able to control fission at the moment; at best, criticality $(K \geq 1)$ can be controlled by stopping the reaction. There are more technological experimentation and unsolved issues in the nuclear industry than sound science to pinpoint them. Chernobyl was a case in point of a failed experiment.

\subsubsection{Leaks}

The drawbacks of technological experimentation are illustrated by widespread leaks demonstrated by using iodine-129 as a marker. ${ }^{129} \mathrm{I}$ is formed by uranium and plutonium fission in nuclear power plants and in reprocessing facilities. The nuclear reprocessing plants in La Hague (France) and Sellafield (UK) are globally the main sources of ${ }^{129} \mathrm{I}$. But ${ }^{129} \mathrm{I}$ reemission from the sea surface in the English Channel, and the Irish, North, and Norwegian seas, is the main ${ }^{129}$ I source washed out in precipitation farther away, in Denmark (Hou et al., 2009a). Atmospheric transport from the Marcoule (France) nuclear reprocessing plant (closed in 1998 after 40 years of emissions) is evidenced by enriched levels of ${ }^{129} \mathrm{I},{ }^{238} \mathrm{Pu}$, and ${ }^{239+240} \mathrm{Pu}$ in collected terrestrial vegetation samples in Marcoule's vicinity. Farther away, activity and depositions follow a North-South direction related 
to atmospheric discharges; these eventually meet the Rhone River (Duffa and Fréchou, 2003) and so enter another environmental compartment in a highly populated area. The same pattern of surface water ${ }^{129} \mathrm{I}$ pollution occurs in Western Europe, North America, and Central Asia, especially in terrestrial surface water of the Northern hemisphere $\left(50^{\circ} \mathrm{N}\right)$. Topmost ${ }^{129} \mathrm{I}$ concentrations are found in England, followed by Israel, Europe, and North America. Direct gaseous emissions from the nuclear facilities and marine atmospheric reemissions are the most probable sources of ${ }^{129}$ I polluting terrestrial surface waters (Chen et al., 2015).

Organic forms of iodine are highly bioavailable to humans through ingestion (via water and plants). After transport to the thyroid, this organ is exposed to long-term, low-dose, beta radiation from decaying ${ }^{129} \mathrm{I}$ (half-life 15.7 million years). More nuclear power plants and more spent fuel reprocessing would largely increase ${ }^{129} \mathrm{I}$ levels (Hou et al., 2009b). As for uranium, cleanup of mill sites has cost U.S. taxpayers in excess of USD 2 billion; in its U(IV) state, it accumulates in cool anoxic sediments where it adsorbs to natural organic matter (Bone et al., 2016).

\subsubsection{Waste}

Perhaps the most difficult, and as yet unsolved, issue for the global nuclear power industry is final confinement of spent nuclear fuel. This is a limiting factor to the expansion of that industry. No solution has yet been found, and no alternative to the leaks from La Hague, Sellafield, and similar facilities. Another kind of uncertainties, geological this time, are met by permanent disposal of waste, according to the U.S. National Academy of Sciences: not all uncertainties can be allayed by research and development as, over geological time, volcanism, behavior of the (un)saturated zones, geochemistry, and climate will evolve. Fundamental properties of the rock are further disrupted by tunnels and the fractured zone they create. Moreover, a radioactive heat pulse creates pore water movements (Ramana, 2017).

These factors led to the closure in 1998 of the Morsleben (Germany) nuclear waste storage since salt domes are on the verge of collapse despite temporary stabilization. In Asse II, the overlying rock shifts $15 \mathrm{~cm} /$ year, weakening the mine; the increasing rate of new water breaches predicts uncontrollable water inflow with ensuing collapse hazard. Brine has to be captured before it reaches the storage canisters and accelerates radioactivity-induced corrosion.

Geology is not the only set of risks in final confinement. In the WIPP facility in New Mexico, an alleged error in packaging material (Figure 2.2) caused an explosive release of plutonium and americium, which reached the surface. The accident, one of the costliest in the U.S. (Ramana, 2017), provoked the closure of the facility in 2014.

\subsubsection{Accidents AND the Human Factor}

Regarding the WIPP accident, one assertion by the U.S. Department of Energy was that some of the organizations managing WIPP had let the safety culture deteriorate (Ramana, 2017). The case of the Indian nuclear industry is also well documented: incidents occur in reprocessing plants, involving the security systems and widespread lack of learning culture, safety culture, and justice (blame shifting from managers to operators) (Ramana and Kumar, 2013). Recurrent failures occur in the same components of the reactors (Figure 2.3).

\subsubsection{Nondemocratic Practices}

The nuclear power industry is therefore exposed to design, human, and institutional failures. Two resounding cases of institutional failures are the San Onofre nuclear power plant scheduled for decommissioning by 2030-31, and the Hinkley C reactor currently in the early construction phases. San Onofre was closed in 2012 following a USD 680 million investment aimed at adding 40 years to its useful life and instead precipitating its demise. As per an open records request to the U.S. Nuclear Regulatory Commission, San Onofre's operators seem to have recklessly pushed the reactor for the 


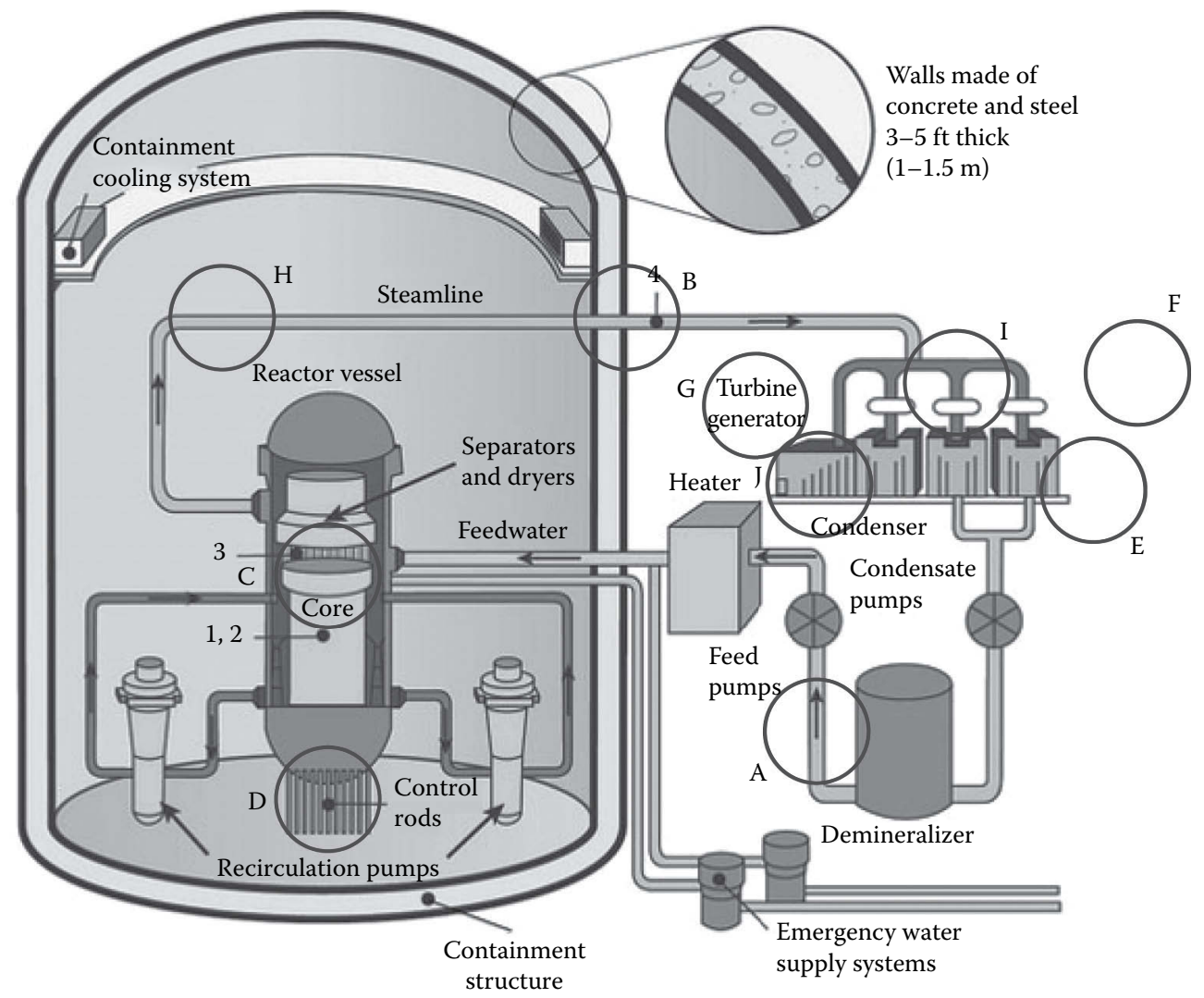

FIGURE 2.2 Typical failures and incidents in Indian nuclear reactors. (a) Madras 2 cool water plug slipped away (1999) and a large amount (4-14 tons) of heavy water leaked out. (b) Large tritium release to the atmosphere in Rajasthan (2004): high levels of tritium in the liquid discharges in Narora and Kakrapar (2003). (c) Fortuitous hole in the primary heat transfer system as a result of an eroded wall in Rajasthan 2 (2007). Three heavy-water leaks elsewhere (2009). (d) Failure of the moderator inlet receiving heavy water at high speed, in Madras (1989). (e) Excessive vibration in the turbine bearings and oil leaks in Narora (1993). This led to sparking (1981). (f) Vibrations in turbine bearings and failure in turbine blades (1982). Vibrations in the turbine generator bearings and blades sheared off at the base (1983). (g) High bearing vibrations in the turbine generator in Madras 1 (1986), similar to Rajasthan 1 (1985, 1989, and 1990). (h) Oil leak in the generator transformer in Madras 1 (1988), with heavy sparking in Madras 1 (1989) and twice in the turbine generator in Narora 1 (1992). (i) Two fires in the primary heat transport system, oil leak in the turbine valve. (j) Hydrogen gas leak in the generator cooling system in Madras 2 (1991). (From Nuclear Regulatory Commission, 2015. Boiling Water Reactors. Retrieved May 2, 2017, from nrc.gov/reactors/bwrs.html, 2015; Ramana, M. V., and Kumar, A., J. Int. Stud., 1, 49-72, 2013.)

sake of profit, leading to definitive damage. The operators later sued the Japanese provider as allegedly responsible for the damage. Then, the USD 4.7 billion settlement between the operators and the California Public Utilities Commission (CPUC) included a clause, which left USD 3.3 billion to be paid by the ratepayers. California's attorney general has opened a criminal investigation against the president of CPUC on grounds of possible collusion between the state regulator and San Onofre operators. This is also the cause for a USD 16.7 million fine to one of the operators (Herchenroeder, 2016; McDonald, 2017). The California Coastal Commission then unanimously approved underground confinement of San Onofre's spent fuel after 15 months of negotiations behind closed doors with the operators. While legal, the closed-door sessions gave a lengthy lead time to the operators 


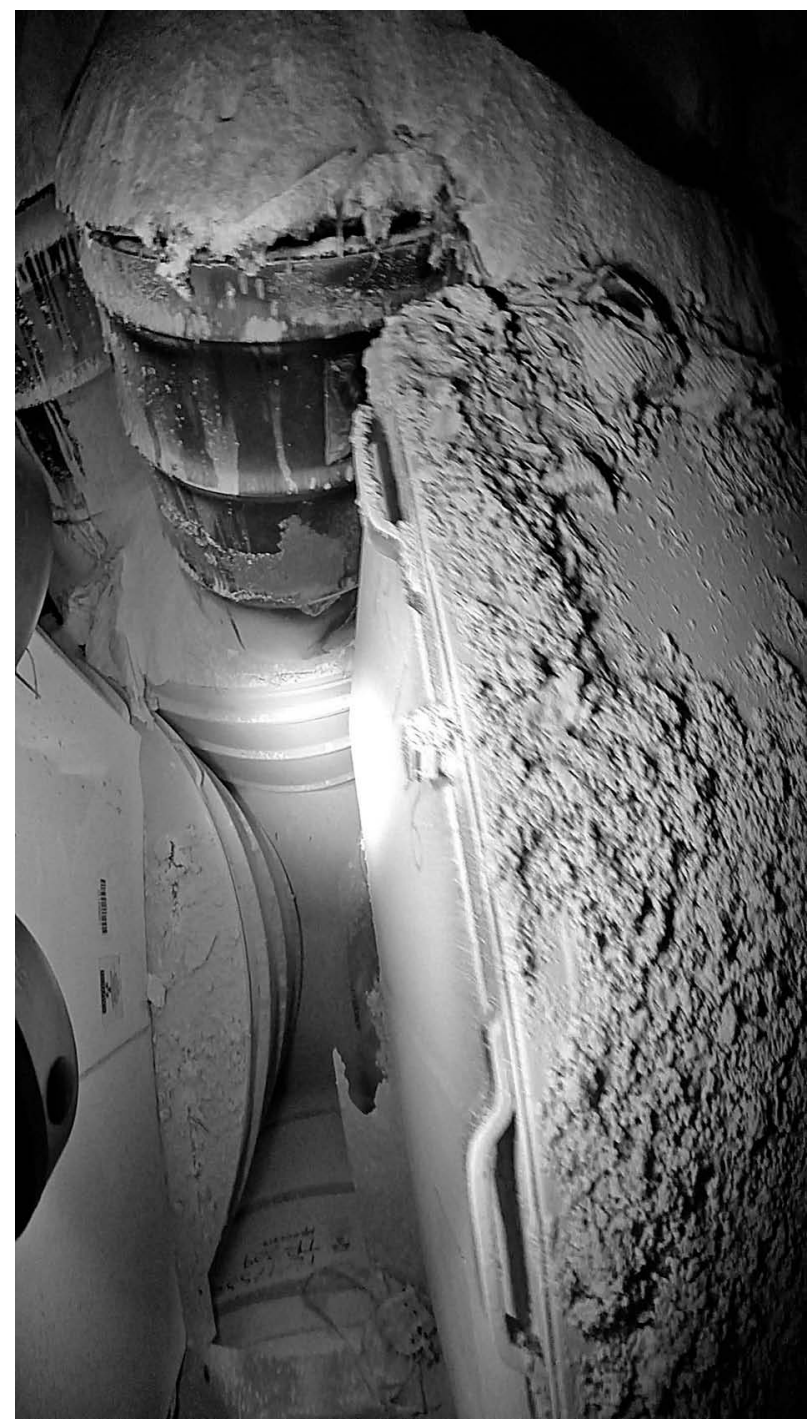

FIGURE 2.3 Damaged drum with radioactive waste inside WIPP Panel 7, Room 7, New Mexico, USA, 2014-05-15 during investigations on the cause of radioactive contamination. (DoE Photographer, damaged drum with radioactive waste inside WIPP Panel 7, Room 7, New Mexico, USA, 2014-05-15 during investigations on the cause of radioactive contamination. Retrieved June 4, 2017, from https://en.wikipedia.org/wiki/ File:WIPP_DoE_2014-05-15_5_15_Image_lrg.jpg, 2014.)

but only a week's notice to the public, before the hearings and decision. As a consequence, a lawsuit against the Coastal Commission was allowed to proceed (Nikolewski, 2017; Sharma, 2017). These issues have prompted Californian municipalities to opt for community choice aggregation (CCA), a scheme giving more say to citizens in energy matters and the possibility to transition to renewable energy; in turn this has led to the emergence of a lobby group against CCA, funded by one San Onofre operator (Smith, 2017).

In Britain's Hinkley C project, the government seems to have ended wind power subsidies and cut back solar subsidies while giving unwavering support to nuclear power. The decision of the government was made despite higher costs of nuclear electricity, faulty components in the same-design plants having led the French authorities to stop several plants, and an indictment by U.S. authorities 
against the main Chinese financial backer of Hinkley C. Chinese financial support was agreed to at the top executive level in exchange of Britain purchasing a small modular reactor (SMR), and the indictment was caused by unauthorized technology exports from the U.S. to China in relation to said modular reactor. In secret documents that the British government refused to disclose under a Freedom of Information request, the government also pledged to bear overrun costs, in particular waste disposal costs. While the government stands by the French and Chinese corporations involved in Hinkley C, the UN Economic Commission for Europe asked the UK to suspend work on the site, pending notification of potential impacts of Hinkley $\mathrm{C}$ to Germany, Norway, and Holland in line with transboundary pollution treaties (Dombey, 2016; Doward, 2016; Vaughan, 2016, 2017; Vaughan and Willsher, 2016).

\subsubsection{Small Modular Reactors: Killed in the U.S., a Return Would Spread the Issues}

SMRs like all nuclear power are unprofitable since the raw material, construction, production, and maintenance are globally dangerous and are extremely costly compared to other industries. Even the leading SMR developers Babcock \& Wilcox and Westinghouse, who had obtained increasing federal SMR subsidies, decided to stop the development of SMR technologies for lack of customers and investors. Westinghouse decided to focus on decommissioning existing reactors (Cooper, 2014). Despite the lack of market in the U.S., other countries pursue SMR development probably due more to government subsidies than market interest. SMR designs claim that there are only four problems identified with nuclear power today: costs, safety, waste, and proliferation. Countries like the U.S., Russia, China, France, Japan, South Korea, India, and Argentina intend to develop SMRs based on subsidies; however, the characteristics of the different SMR designs under development suggest that none of the designs meet all four of these challenges simultaneously (Ramana and Mian, 2014).

\subsubsection{Medical and Scientific Uses Require Few Reactors}

The global demand for medical isotopes requires only a couple of experimental reactors, since at one time the small Chalk River reactor in Canada supplied half the world's requirements (Harris, 2014). As for fundamental physics requirements, they would be better served by a few well-characterized hence comparable reactors. At the turn of the century, the U.S. Department of Energy recommended only the use of existing facilities to further science and supply civil nuclear uses (DoE, 2000).

\subsection{MILITARY DRIVERS OF NUCLEAR POWER}

The top global strategic topics are, in decreasing importance, energy and weapons. Indeed, one justification for civil nuclear power has been to obtain weapons-grade uranium or plutonium, through at least four pathways: uranium enrichment, heavy water reactors that do not require enrichment, plutonium production reactors, or plutonium waste from a civil reactor followed by reprocessing. The UN Security Council $5+1$ countries have tried to monitor these pathways to curtail nuclear weapons proliferation, with either bias or lack of success: the production of atomic weapons by India, Pakistan, and Israel has complicated the political and military arena in Western and Southern Asia. Tension escalation in Eastern Asia following tests in North Korea and a standoff in the South China Sea might lead Japan and South Korea, caught in the regional game for supremacy between the U.S. and China, to a rather simple transfer of civil to military nuclear wherewithal. Germany might also try to compensate for lessened protection from post-Brexit UK and U.S. withdrawal from NATO, although it may become patent that Helmut Kohl's Germany had purchased Soviet missiles and they were left behind when the Red Army left Eastern Germany.

However, the usefulness of nuclear deterrents after the Cold War is now denied by a bipartisan group of former U.S. State and Defense Secretaries (Shultz et al., 2007-2011). They call for urgent 
and complete nuclear disarmament, prevention of accidental detonations, phaseout of commercial and scientific uses of highly enriched and weapons-grade materials, and prevention of regional conflicts. Other former defense and state secretaries, national security advisors, and Western and Asian former heads of state endorse their views. Additional arguments against nuclear weapons are, on the one hand, technical advances in conventional arms that make several nuclear goals and missions obsolete (Oelrich, 2005). On the other hand, new warfare fields, namely terrorism and cyberattacks, are exposing vulnerabilities of nuclear defenses.

At the time of writing, higher risks of nuclear proliferation exist under the new Trump administration. The remainder of this chapter will nevertheless address the hitherto little-studied field of nuclear power security from a military point of view (drawing on firsthand experience in the Iranian civilian program). This is motivated by two facts: power generation is the first target of any military attack, and a provoked nuclear power plant accident can be an extremely contaminant event, able to impair a country's defenses in a large region.

\subsubsection{Nuclear Power Is Oil Dependent and Security Intensive}

Most of the nuclear energy life cycle is fossil fueled, from mining and transportation to initial centrifugation, many backup systems, massive concrete and burrowed buildings to shelter the nuclear reactors, the manufacture of all reactor components, their maintenance, and finally plant decommissioning, dismantlement, and cleanup. In 14 U.S. states, there are around 15,000 abandoned uranium mines still not cleaned up.

The security of the nuclear industry is also very energy intensive. Nuclear energy is cumbersome: aerospace experiments are few, and along with nuclear submarines and carriers are the preserve of the major nuclear powers. Air strikes and troop deployment critically depend on oil. Additional oil consumption stems from military vehicles and systems protecting nuclear power plants around the world. Security and safety (2S) costs also include multilateral agencies (UN Security Council and IAEA), nuclear industry public representation, and diplomacy. Other costs are the physical enforcement of technology secrecy and safekeeping of the always weaponizable waste. The recovery of lost/stolen devices and material, which seems to occur or be reported more often in the U.S., is an additional military and police task (CNS, 2017).

Although nuclear power is probably not viable beyond the exhaustion of oil reserves, this dependency of nuclear power on oil exacerbates the armed conflicts around the dwindling yet ever less profitable, oil reserves.

\subsubsection{Cyberwarfare, Intelligence, And Complexity}

In 2010, a computer program later nicknamed Stuxnet was introduced by a mole using a USB drive in the computer system of the Natanz nuclear enrichment plant in Iran. The program remained dormant for a month and then took control of the Siemens system driving the centrifugation enrichment process; all displays appeared to be normal until the backup system kicked in. The attack seemed to pertain to the U.S. Olympic Games covert operation carried out by U.S. and Israeli agencies. Retaliation was not direct and instead targeted the Saudi oil company Aramco network of computers. Internationally, these are construed as attacks. In nuclear power plants, exploiting code vulnerabilities is a chief factor complicating security, as many systems are computerized in the man-computer-robot environment of a plant (Figure 2.4).

Cyberwarfare adds complexity to secrecy, an indispensable element of security, but one that contributes to noncivilian, nondemocratic control of nuclear power. In turn, intelligence has two components that can easily conflict with one another, although both are concerned with monies: on the one hand, military intelligence is the part of the military that checks, controls, and rechecks the planning and programming of an operation so it can meet several objectives, within a stated uncertainty (Figure 2.5). On the other hand, intelligence in the sense of espionage is much less 


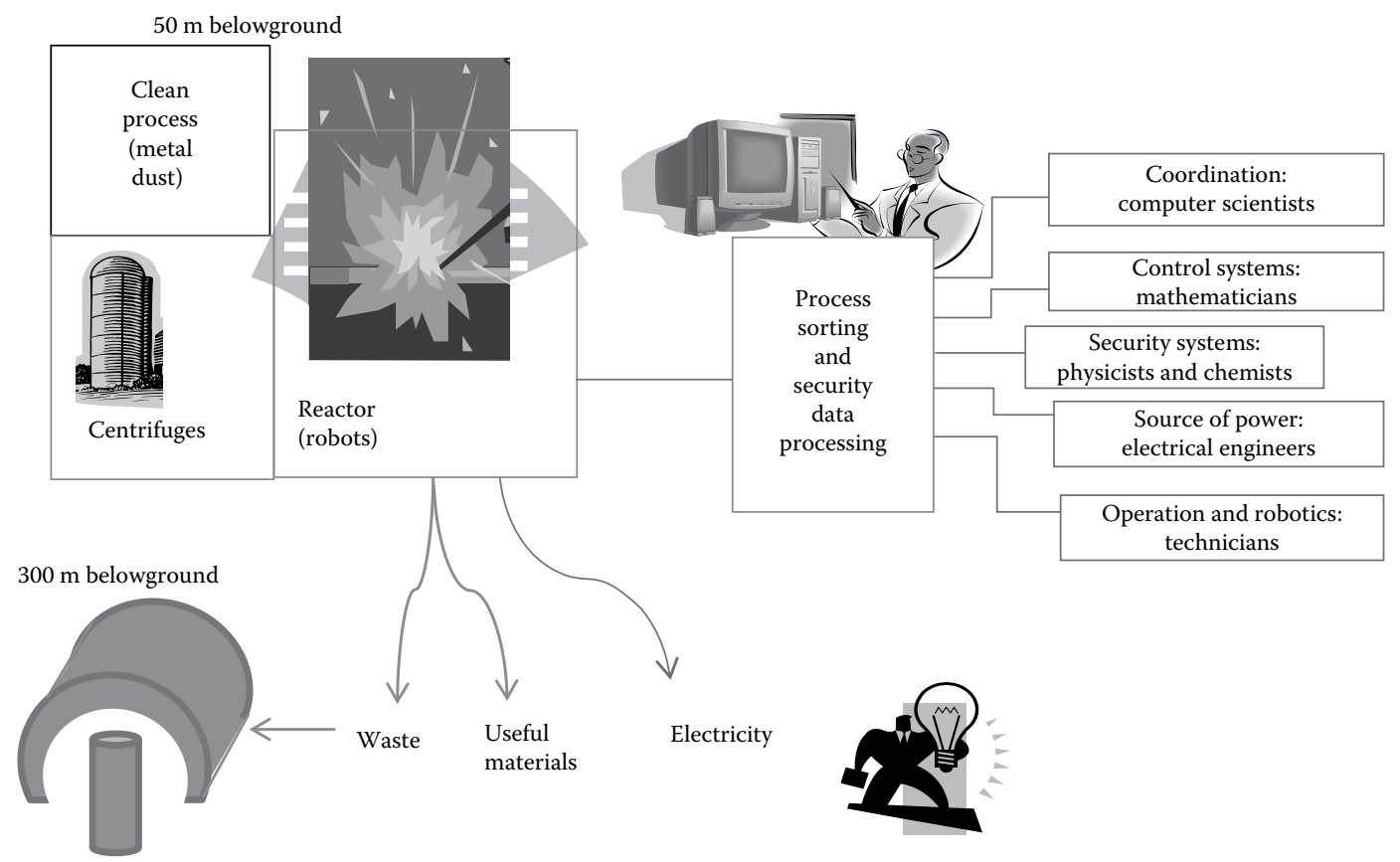

FIGURE 2.4 Vulnerability areas in the human-computing interface of a nuclear power plant (thick lines and outlines). Vulnerabilities are numerous in real life. The main risks are as follows: (1) nuclear fission energy > electricity output; (2) attack to the centrifuges; (3) external cyber- or physical attack during the recovery from heavy seismic event, and/or technical failure and/or (cyber) attack; and (4) simultaneous electromagnetic pulse (via nuclear detonation) to knock down all electronic systems and neutron bomb (to kill all human operators). Issues can occur simultaneously as shown in Fukushima.

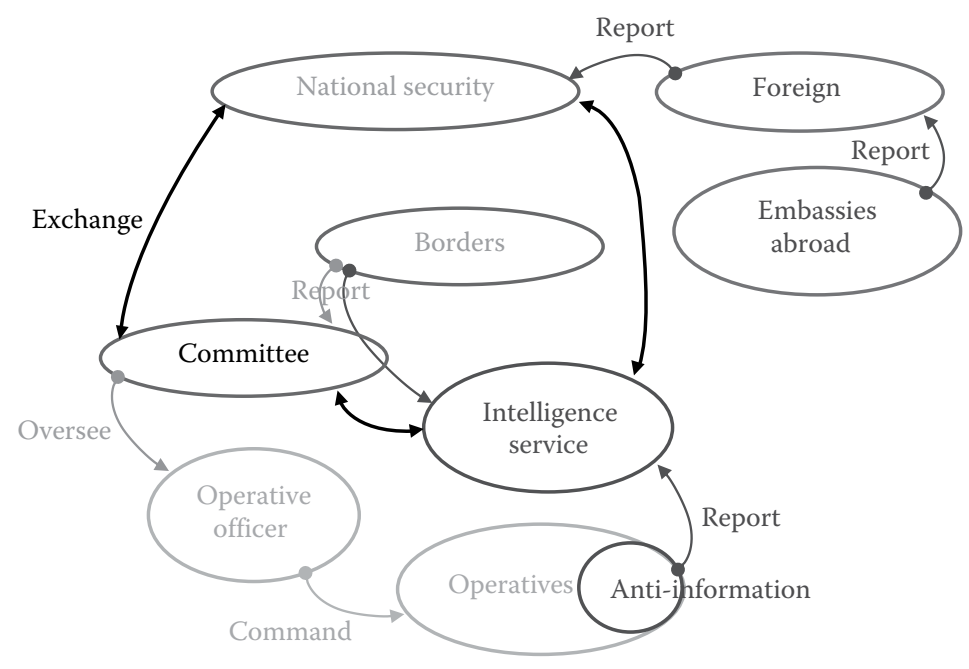

FIGURE 2.5 Intelligence in the Iranian nuclear context. Schematic of the complex information flows between nuclear plant operatives and intelligence services. The information is both administrative (concerning approved monies and reporting deadlines) and operative. The tricky part for operatives is to always keep a flexibility margin to accommodate for nonplanned events. Information from abroad is a very early warning but can in fact be disinformation. 
predictable, as its stock-in-trade is mediation in transactions involving arms, politics, and, often, fuels. The case of Irangate is well known. Another well-documented example (showing that espionage overcomes national loyalties and is driven by profit) is the arms trade that was set up in 2010 by Arthur Porter, head of the Security Intelligence Review Committee in Canada; former Israeli intelligence officer Ari Ben-Menashe; and Russian arms dealers to provide Sierra Leone with arms of unknown origins (Harris, 2014). Profit as a motive makes for fickle allegiances and so is a challenge to the security of national assets. Intelligence and cyberwarfare demonstrate that ever more complex security systems beget additional vulnerabilities.

\subsubsection{IDEOLOGY AND OIL}

Ideologies, sensu Immanuel Wallerstein, are strategies in the pursuit of global hegemony. The U.S. now dominates the world in military terms. U.S. national security is based on long-term plans elaborated by the CIA with a say from the American Israel Public Affairs Committee (AIPAC) lobby; in such plans, the probability of remaining the only superpower is gauged against time: the U.S. will retain the hegemony with a $100 \%$ probability within 2 years, $50 \%$ probability within 25 years, and $25 \%$ probability within 50 years. These plans were uncovered when the U.S. embassy in Tehran was taken over in 1979. But the Middle East challenges the U.S. global hegemony. The region has grown into a matrix of interconnected countries spanning the area between Israel and India, Southern Republics of the Community of Independent States, and Iran. They are connected by fossil fuel reserves, terrorism, and nuclear threats.

\subsubsection{Hegemony and Instability (Divide and Rule)}

Terrorism has not yet materialized as a threat, but there is enough material being lost or stolen for the danger of radiological dispersal devices to be considered. More acute is the complexity added by terrorism to the global geopolitical situation. Terrorism is the protracted outcome of the Cold War and the struggle of the U.S. toward global hegemony: it was the brainchild of Zbigniew Brzezinski, National Security advisor to U.S. President Jimmy Carter, aimed at making the Soviet invasion of Afghanistan difficult; it was called the Green Belt. The USSR wanted to follow up on the tsars' geopolitical view: we must reach the Persian Gulf. Ethnic groups from the USSR retreated to Pakistan. Ronald Reagan followed up on Brzezinski and used Mujahidin, revolution in Iran, radicalism in Turkey, Saddam Hussein in Iraq, and Shiites vs. Sunnites in Lebanon. The reaction from a segment of the population in those countries was to emigrate to Europe. The problem was the same for them as for North Africans: second-generation "migrants" (i.e., European citizens) were discriminated against and disenfranchised. Years later, a marginal fraction of these people became the network of Daesh terrorists sent from Syria to Europe.

Brzezinski's strategies also damaged the SENTO confederation that included Iran, Jordan, Oman, Egypt, Turkey, and later Iraq, Syria, and South Yemen. It was a counterweight to NATO and the Warsaw Pact. Its demise coincided with U.S. support to the Mujahidin and the accession to power of Khomeini and Bhutto in Iran and Pakistan, respectively.

In addition, the U.S. has fueled the religious conflict between Iran and Saudi Arabia (SA), to divide OPEC and weaken Iran's position, formerly OPEC's top oil producer. SA has used its oil production to decrease the oil prices in order to slow Iran's development. In the Iran-Iraq war, Iraq was supported by SA, vying for regional resource control. At one time, SA offered to pay Iran to leave Iraq and let go of 250-300 km of land gained during the conflict. More recently, the armed conflicts by proxy between SA and Iran are taking place in Yemen and Syria.

\subsubsection{The Next Oil Wars}

George W. Bush changed strategy: the U.S. took direct military action in Iraq to gain control over energy reserves. Further control was sought by the presence in the Persian Gulf of the U.S. Navy, to curtail the control by Iran of the Strait of Hormuz. Through the Strait, a vast amount of all the oil 
in the world transits; $90 \%, 60 \%$, and $40 \%$ of the Chinese, Japanese, and Korean fossil fuel supplies come from Iran.

When the Democrats took over from G.W. Bush, they returned to action by proxy, such as in the 2011 Arab Spring, but the end result there is that Libya is now divided between Daesh and the rebels; Egypt is led by Eghnan El Muslemi after two successive coups; Syria is struggling against Daesh (which has received help from SA, Turkey, and Qatar, a fact well known by Department of State secretary Hillary Clinton). One must note that after the destruction of Saddam Hussein's army by the U.S. and allies, removed Iraqi officers went on to constitute half of Daesh's forces; 25,000 warriors were also brought in from Europe. At stake in the conflict in Syria is the control of oil reserves, where Daesh receives support from the Erdogan regime in Turkey, acting as mediator of BP's oil interests.

Future oil wars will depend on the outcome of the conflict surrounding Syria, but likely next oil conflicts will include Sudan (oil) and then Somalia (gas). Already, gas reserves motivated the annexation of Crimea by Russia in 2014. The region holds the most gas reserves in the world (Iran > Russia > Qatar).

\subsubsection{Realpolttik among the U.S., Israel, and Iran}

One can only understand the U.S.-Israel relationship under the prism of pragmatism on both sides. Israel's foreign policy relies on support from abroad and especially lobbying in the U.S. through AIPAC. Often, but not always, the U.S. and Israel are strategic partners: Israel also buys military technology from Russia and Europe as a way of gaining political and military support. Moreover, Israel has sold U.S. weapons to China.

Conversely, the U.S. does not depend on Israel alone in the Middle East: they also partner with NATO member Turkey, Bahrain (to station the fifth U.S. fleet), Kuwait, SA, and occasionally with Egypt. The link between SA and the U.S. hinges on SA's holding USD 800 billion in the U.S. stock exchange and USD 900 billion in the treasury in Ryad. As to Pakistan, which harbors terrorist groups, it receives around USD 15 billion each year, because the U.S. pursues the logic of "divide and rule" in Afghanistan.

Similarly, the relationship between Israel and Iran has been marked by the will of Menachem Begin to use nuclear weapons against Iran, stopped by Israel's Defense Minister in 1967. Later, 15,000 Israelis were allowed to volunteer in Iran against Iraq, but Iran refused the offer. During the Iran-Iraq war, Iran and Israel successively bombed an Iraqi nuclear power plant. As for Irangate, Iran helped the U.S. control Saddam Hussein, since the U.S. could not fly above the Oman Sea; sanctions motivated by the Iranian nuclear program were lifted; and the U.S. intended to buy nuclear fuel and waste from Iran; this all demonstrates the variability of the mutual attitude of the U.S. and Iran.

\subsubsection{The Quest for Energy Autonomy and Nonalignment}

History has shown that treatises and alliances have many times been flouted. History also shows the very high costs of keeping nonaligned. In particular, $2 \mathrm{~S}$ costs of nuclear power are very high.

\subsubsection{Security Lessons from Chernobyl}

Assessments of the Chernobyl catastrophe have failed to ascertain the strategic facet. The collapse of the reactors partly resulted from Soviet security decisions to suspend support to Ukraine. To understand the rationale of Soviet nuclear security, three principles are worth recalling: first, that to withstand attacks, the technology had to be deployed in several Republics; second, that Russia was central, Ukraine peripheral, and Kazakhstan marginal; and third, that technology needed to be only partially transferred to be controlled. Accordingly, uranium from the reactors in Kazakhstan and 
Ukraine left with $70 \%$ purity for Leningrad to be upgraded to $90 \%$ and then used in warheads; in the opposite direction, nuclear waste flowed from Russia to Kazakhstan. The Soviet technological withdrawal was completed in 1988, when the USSR returned the nuclear scientists to Russia. This left Chernobyl operating until international pressure forced its closure in 2000.

The lessons learned by Iran from Chernobyl include the following:

- Security is often sought at the expense of safety (i.e., public health and the environment).

- To operate a technology is not to learn and master it.

- Energy independence depends on diversifying energy sources and technologies. This is why Iran has developed technologies for the whole nuclear and oil production chains and invested in wind power (e.g., in Manjil near the Caspian Sea).

- A host of $2 \mathrm{~S}$ criteria needs thorough and continually updated seismology, oceanology, climate, weather, geology, soils, transportation, and military risk maps.

- Corruption is incompatible with $2 \mathrm{~S}$ and is avoided via supervision of a nuclear plant by a consortium where universities sit alongside the military and the Institute of Atomic Energy (in contact with the IAEA in relation to basic standards). In turn, the military is controlled, in Iran, by three intelligence agencies belonging to the military, the Presidency, and the High Committee for National Security. Foreigners are only consultants with short contracts.

- The politicians do not supervise the nuclear power plants; these respond to technical and $2 \mathrm{~S}$ principles, although building a plant is decided by politicians.

\subsubsection{Security Lessons from Furdu}

- Trade-offs are difficult to achieve: the Furdu nuclear plant in Iran was located in the mountains, $300 \mathrm{~m}$ below ground, but far from where electricity output could be consumed.

- Furdu was deeper inside Iran and better than the Busher nuclear plant that, if bombed, would irradiate all of the Persian Gulf.

- Furdu is located within a very narrow viewshed, to delay immediate radiation propagation, and reduce the time frame available to supersonic bombers. Furdu was also equipped with the latest Russian S300 antiaircraft defense.

- The dedication of scientists has to border on total seclusion.

- $2 \mathrm{~S}$ decisions can be misinterpreted and cause security tensions with other countries: Furdu's seclusion was one element presented by the U.S. suggesting that Iran might want to avoid scrutiny and pursue military use of Furdu. This opened a possibility for an Israeli attack.

- In 2008 the U.S. promoted a vote in the UN Security Council to attack Iran, which was vetoed by Russia and China; this cost Iran a wide market opening to Chinese products and the Iranian industries, and jobs suffered substantially as a consequence.

\subsubsection{Nuclear Security and Sustainability}

Peace is essential to sustainability. Proliferation control will not make nuclear energy a solution for all nations. Nuclear power itself breeds instability: waste can lead to both proliferation and terrorism. At present, proliferation is not checked but used in the triple confrontation among U.S., Russia, and China, each of which supports different nations in the Middle East and the Korean peninsula.

An enemy abiding by Geneva rules will not attack civilian populations but rather strike the energy system (nuclear, oil, and electric supplies); then, if electricity is down, communications are down; if petroleum is down, transportation is down. Paradoxically, within Geneva rules, preemptive strikes and open war make nuclear power plants very large liabilities in terms of nuclear fallouts affecting human and natural populations. 
Natural phenomena occur in energy ranges that challenge any human structure, and so there is hubris in claims that plants can withstand bombing, technical failure, or extreme environmental events in close succession. This is now complicated by cyberwarfare. Attacks would likely profit from concurring challenges to a nuclear plant.

There is often a security-safety balance to strike. For example, an aboveground oil duct is good for safety, since leaks are readily visible but very vulnerable in security terms. Often the environment pays the higher costs. The intuition of isolation as source of security and safety hardly withstands an examination of material flows (oil, uranium, and other wares) that cross borders. Isolation from natural phenomena is even more questionable.

Energy is a national security matter, and civil nuclear power without military security management is unfeasible. This also moves the nuclear industry beyond the pure market economy. Also, nuclear technology and operations cannot be transparent. Hence, decisions thereupon cannot be democratic, for security reasons. Complex systems are ideal for nondisclosure and for heavy subsidies. Nondisclosure is good for security but very bad for safety and democracy. Population control by intelligence agencies on grounds of terrorism prevention and covert operations motivated by profit are causes for concern. Where information is lacking, extremism can flourish. $2 \mathrm{~S}$ is all about protocols, best kept secret. But many crucial reactions to alerts draw on experience rather than protocol.

Control systems, including $2 \mathrm{~S}$, are themselves subject to failure. The inherently high complexity of nuclear fission technology is thus amplified by complex but fallible security systems and a dynamic geopolitical environment. In the future, heightened complexity can make more issues intractable.

\section{REFERENCES}

Al-Adili, A., Alhassan, E., Gustavsson, C., Helgesson, P., Jansson, K., Koning, A., Lantz, M., Mattera, A., Prokofiev, A. V., Rakopoulos, V., and Sjöstrand, H. (2015). Fission activities of the nuclear reactions group in Uppsala. Physics Procedia, 64, 145-149. doi:10.1016/j.phpro.2015.04.019.

Armstead, H. (1983). Geothermal Energy (p. 404). London: E. \& F. N. Spon.

Baba, A., Deniz, O., Ozcan, H., Erees, S. F., and Cetiner, S. Z. (2008). Geochemical and radionuclide profile of Tuzla geothermal field, Turkey. Environmental Monitoring and Assessment, 145, 361-374. doi:10.1007/ s10661-007-0045-0.

Bastin, J.-F., Berrahmauni, N., Grainger, A., Maniatis, D., Mollicone, D., Moore, R., Patriarca, C., Picard, N., Sparrow, B., Abraham, E. M., and Aloui, K. (2017). The extent of forest in dryland biomes. Science, 356, 635-638.

Bone, S. E., Dynes, J. J., Cliff, J., and Bargar, J. R. (2016). Uranium(IV) adsorption by natural organic matter in anoxic sediments. PNAS, Early Edit, 1-6. doi:10.1073/pnas.1611918114.

Bonner, J. (1962). The upper limit of crop yield. Science, 137, 11-15.

BP. (2016). Statistical Review of World Energy (65th ed.). London: BP plc.

Chen, X., Gong, M., Yi, P., Aldahan, A., Yu, Z., Possnert, G., and Chen, L. (2015). Nuclear Instruments and Methods in Physics Research B I in terrestrial surface water environments. Nuclear Instruments and Methods in Physics Research B. doi:10.1016/j.nimb.2015.04.073.

Clarke, L., Robinson, S., Hua, Q., Ayre, D., and Fink, D. (2012). Radiocarbon bomb spike reveals biological effects of Antarctic climate change. Global Change Biology, 18, 301-310. doi:10.1111/j.1365-2486.2011.02560.x.

CNS. (2017). Global Incidents and Trafficking Database. 2016 Annual Report (pp. 1-24).

Cooper, M. (2014). Small modular reactors and the future of nuclear power in the United States. Energy Research and Social Science, 3, 161-177. doi:10.1016/j.erss.2014.07.014.

Cowan, R. (1990). Nuclear power reactors: A study in technological lock-in. The Journal of Economic History, $50,541-567$.

De Vos, A. (1995). Thermodynamics of photochemical solar energy conversion. Solar Energy Materials and Solar Cells, 38, 11-22.

DoE Photographer. (2014). Damaged drum with radioactive waste inside WIPP Panel 7, Room 7, New Mexico, USA, 2014-05-15 during investigations on the cause of radioactive contamination. Retrieved June 4, 2017, from https://en.wikipedia.org/wiki/File:WIPP_DoE_2014-05-15_5_15_Image_lrg.jpg. 
Dombey, N. (2016 August 16). Letter. The Guardian. London.

Doward, J. (2016 October 30). Secret government papers show taxpayers will pick up costs of Hinkley nuclear waste storage. The Guardian. London.

Duffa, C., and Fréchou, C. (2003). Evidence of long-lived I and Pu isotopes enrichment in vegetation samples around the Marcoule Nuclear Reprocessing Plant (France). Applied Geochemistry, 18, 1867-1873. doi:10.1016/S0883-2927(03)00148-3.

Field, C. B., Behrenfeld, M. J., Randerson, J. T., and Falkowski, P. (1998). Primary production of the biosphere: integrating terrestrial and oceanic components. Science, 281, 237-240.

Great East Japan Earthquake Taskforce \& Science Council of Japan. (2011). Report to the Foreign Academies from Science Council of Japan on the Fukushima Daiichi Nuclear Power Plant Accident (pp. 1-25). Retrieved from http://www.scj.go.jp/en/index.html.

Greenpeace. (2006). Executive summary, p. 10. In A. Yablokov, I. Labunska, I. Blokov, R. Stringer, D. Santillo, P. Johnston, and T. Sadownichik (Eds) The Chernobyl Catastrophe. Consequences on Human Health. Amsterdam: Greenpeace.

Gundersen, A. (2016). Nuclear Power Is Not 'Green Energy': It Is a Fount of Atomic Waste. Truthout New Analysis. Retrieved from truth-out.org/news/item/38326-nuclear-power-is-not-green-energy-it-is-afount-of-atomic-waste.

Haegel, N. M., Margolis, R., Buonassisi, T., Feldman, D., Froitzheim, A., and Al., E. (2017). Terawatt-scale photovoltaics: Trajectories and Challenges. Science, 356, 141-143.

Harris, M. (2014). Party of one (534 pp). Toronto: Viking.

Herchenroeder, K. (2016). SCE Fully Responsible for SONGS Shutdown: Report. RadWaste Monitor. Retrieved from exchangemonitor.com/publication/rwm/sce-fully-responsible-for-songs-shutdown-report/.

Hou, X., Aldahan, A., Nielsen, S. P., and Possnert, G. (2009a). Time series of 129I and 127I speciation in precipitation from Denmark. Environmental Science and Technology, 43, 6522-6528.

Hou, X., Hansen, V., Aldahan, A., Possnert, G., Christian, O., and Lujaniene, G. (2009b). A review on speciation of iodine-129 in the environmental and biological samples. Analytica Chimica Acta, 632, 181-196. doi:10.1016/j.aca.2008.11.013.

IAEA. (2013). Management of NORM Residues. IAEA-TECDOC-1712 (p. 66). Vienna: International Atomic Energy Agency.

Ireland, D. and Nazarewicz, W. (2015). Enhancing the interaction between nuclear experiment and theory through information and statistics. Journal of Physics G: Nuclear and Particle Physics, 42, 1-3. doi:10.1088/0954-3899/42/3/030301.

Kopp, G., and Lean, J. L. (2011). A new, lower value of total solar irradiance: Evidence and climate significance,. Geophysical Research Letters, 38. doi:10.1029/2010GL045777.

Lubimova, E. A. (1968). Thermal history of the Earth. Geophysical Monograph Series, 13, 63-77.

McDonald, J. (2017). 5 dramas still playing out 5 years after San Onofre shutdown. San Diego Union Tribune. San Diego.

National Research Council. (2015). Climate Intervention: Carbon Dioxide Removal and Reliable Sequestration. Committee on Geoengineering Climatic: Technical Evaluation and Discussion of Impacts (p. 140). Washington, DC: The National Academies Press.

Nikolewski, R. (2017). Judge allows San Onofre waste lawsuit to advance. San Diego Union Tribune. San Diego.

Nuclear Regulatory Commission. (2015). Boiling Water Reactors. Retrieved May 2, 2017, from nrc.gov/reactors/bwrs.html.

Oelrich, I. (2005). Missions for Nuclear Weapons after the Cold War (p. 75). Washington, DC: Federation of American Scientists.

Peixoto, J. and Oort, A. (1992). Physics of Climate (pp. 365-400). New York: American Institute of Physics.

Premuzic, E. T., Lin, M. S., and Lian, H. (1995). Biochemical technology for the detoxification of geothermal brines and the recovery of trace metals. International Conference on Heavy Metals in the Environment, Hamburg (Germany), 18-22 Sep.

Ramana, M. V. (2017). An enduring problem: Radioactive waste from nuclear energy. Proceedings of the IEEE, 105, 415-418.

Ramana, M. V. and Kumar, A. (2013). Nuclear safety in India: Theoretical perspectives and empirical evidence. Journal of International Studies, 1, 49-72.

Ramana, M. V. and Mian, Z. (2014). One size doesn't fit all: Social priorities and technical conflicts for small modular reactors. Energy Research and Social Science, 2, 115-124. doi:10.1016/j.erss.2014.04.015.

Rincón, E. (2011). Por qué las plantas nucleoeléctricas no son una opción conveniente para México. Revista de Energía, 11, 12-13. 
Ryther, J. (1959). Potential productivity of the sea. Science, 130, 602-608.

Sharma, A. (2017). Coastal Commission Met Privately with Edison a Year Before Public San Onofre Waste Storage Vote. KPBS. Retrieved May 30, 2017, from kpbs.org/news/2017/may/30/ public-excluded-key-talks-over-san-onofre-waste-st/.

Shultz, G. P., Perry, W. J., Kissinger, H. A., and Nunn, S. (2007-2011). Toward a World without Nuclear Weapons. The groundbreaking Wall Street Journal op-ed series. Washington, DC: NTI.

Smith, J. E. (2017 May 23). This city could become region's first to offer SDG\&E alternative for electricity. San Diego Union Tribune. San Diego.

Sovacool, B. (2014). Cornucopia or curse? Reviewing the costs and benefits of shale gas hydraulic fracturing. Renewable and Sustainable Energy Reviews, 37, 249-264. doi:10.1016/j.rser.2014.04.068.

Stacey, F. D. and Loper, D. E. (1988). Thermal history of the Earth: A corollary concerning non-linear mantle rheology. Physics of the Earth and Planetary Interiors, 53, 167-174.

Steger, U., Achterberg, W., Blok, K., Bode, H., Frenz, W., Gather, C., Hanekamp, G., Imboden, G., Jahnke, M., Kost, M., Kurz, R., Nutzinger, H. G., Ziesemer, T. (2005). Sustainable Development and Innovation in the Energy Sector (p. 32). Berlin: Springer.

Talou, P., Kawano, T., Chadwick, M. B., Neudecker, D., and Rising, M. E. (2015). Uncertainties in nuclear fission data. Journal of Physics G: Nuclear and Particle Physics, 42, 1-17. doi:10.1088/0954-3899/42/3/034025.

University of Leicester Press Office. (2016). Anthropocene Working Group (AWG). Media Note. Retrieved April 10, 2017, from www2.le.ac.uk/offices/press/press-releases/2016/august/media-noteanthropocene-working-group-awg.

Vaughan, A. (2016 August 11). Solar and wind "cheaper than new nuclear" by the time Hinkley is built. The Guardian. London.

Vaughan, A. (2017 March 20). UN asks UK to suspend work on Hinkley Point. The Guardian. London.

Vaughan, A., and Willsher, K. (2016 December 2). New blow for Hinkley Point contractor EDF after French safety checks. The Guardian, pp. 2016-2018. London.

World Energy Council. (2016). World Energy Resources Geothermal 2016 (p. 54).

World Nuclear Association. (2016). Chernobyl Accident 1986. Retrieved May 15, 2017, from http://worldnuclear.org/information-library/safety-and-security/safety-of-plants/chernobyl-accident.aspx. 